Antifibrinolytic drugs should probably be given for at least four weeks to cover the period during which primary or secondary fibrinolysis continues and the risk of breakthrough bleeding is highest. Indeed, rebleeding in a patient who has had antifibrinolytic treatment may be less serious, as the aneurysm is better protected after the first bleed.

Theoretical side effects ${ }^{30} 31$ of thromboembolism and communicating hydrocephalus from obstruction of the subarachnoid space were not encountered,"1031 even though antifibrinolytic treatment was continued for longer than usual. Progressive neurological deterioration, usually reversible, was common, however, and does not seem to have been a problem when treatment was given for a shorter period, although cases of cerebral arteriopathy $^{6}{ }^{32}$ and delayed cerebral arterial spasm ${ }^{10}$ have been reported.

Progressive cerebral ischaemia may prove to be a serious side effect of prolonged antifibrinolysis in the more obtunded patients, in whom such an occurrence is known to be more frequent. Three of the five patients in Botterell grade 3 who were given tranexamic acid showed this phenomenon, and the failure of large intracerebral clots to dissolve may also prove to be a problem. The death of an obtunded patient given tranexamic acid after the closure of the trial was apparently due to ventricular blockage caused by a persistent clot.

The tentative conclusion to be drawn from these findings, given that the number of patients and length of follow-up were limited, is that prolonged antifibrinolysis may permanently improve the natural history of ruptured aneurysms. If this is so the results of direct aneurysm surgery will have to be measured against a new set of rebleeding and survival risks, and those patients whose aneurysms have configurations or sites not accessible to surgery can be offered an effective non-surgical treatment.

I thank Mr R Campbell Connolly and Mr J C M Currie for permission to carry out this study on their patients at St Bartholomew's Hospital, and Dr Allan Lauder and Dr James Ware of Kabivitrum Ltd for advice and encouragement.

\section{References}

1 Adams, C B T, Loach, A B, and O'Laire, S A, British Medical fournal, 1976, 2, 607.

2 Krayenbühl, H A, et al, fournal of Neurosurgery, 1972, 37, 678.

${ }^{3}$ Symon, L, in Cerebral Arterial Disease, ed R W R Russell, p 231. London, Churchill Livingstone, 1976.

${ }^{4}$ Corkill, G, Medical fournal of Australia, 1974, 1, 468.

${ }^{5}$ Mullan, S, and Dawley, J, fournal of Neurosurgery, 1968, 28, 21.

${ }^{6}$ Norlen, G, and Thulin, C A, Neurochirugia, 1969, 12, 100.

' Ransohoff, J, Goodgold, A, and Benjamin, M V, fournal of Neurosurgery, $1972,36,525$.

${ }^{8}$ Sengupta, R P, So, S C, and Ostega, F J V, fournal of Neurosurgery, 1976, 44, 479.

${ }^{9}$ Smith, R R, and Upchurch, J J, Fournal of Neurosurgery, 1973, 38, 339.

1" Tovi, D, and Fodstad, H. Personal communication, 1977

${ }^{11}$ Mullan, S, in Current Controversies in Neurosurgery, p 259. Philadelphia, Saunders, 1976.

12. Botterell, E H, et al, fournal of Neurosurgery, 1956, 13, 1.

${ }^{13}$ Gordon, Y B, et al, Lancet, 1973, 2, 1168.

14 Pakarinen, S, Acta Neurologica Scandinavica, 1967, 43, suppl No 29.

${ }^{15}$ Locksley, H B, Fournal of Neurosurgery, 1966, 25, 321.

${ }^{16}$ Alvord, E C, et al, Archives of Neurology, 1972, 27, 273.

"Shephard, R H, Choudhury, A R, and Kaisy, F S, fournal of Neurology, Neurosurgery and Psychiatry, 1975, 38, 828.

18 Thomas, D G, and Paterson, A, fournal of Neurology, Neurosurgery and Psychiatry, 1975, 38, 826.

19 Crompton, M R, Fournal of Neurology, Neurosurgery and Psychiatry, 1966, 29, 164 .

20 Tovi, D, Umea University Medical Dissertations No 8, 1972

${ }^{21}$ Maki, M, and Beller, F K, Thrombosis et Diathesis Haemorrhagica, 1966, 16, 668 .

2:- Andersson, $\mathrm{L}$, et al, Scandinavian fournal of Haematology, 1965, 2, 230

${ }^{23}$ Patterson, R H, and Harper, P, fournal of Neurosurgery, 1971, 34, 365.

${ }^{24}$ Uttley, D, and Richardson, A E, Lancet, 1974, 2, 847.

${ }^{25}$ Nibbelink, D W, Torner, J C, and Henderson, W G, Stroke, 1975, 6, 622.

${ }^{26}$ Gibbs, J R, and Corkill, A G L, Postgraduate Medical fournal, 1971, 47, 199.

${ }^{27}$ McKissock, W, et al, Lancet, 1964, 1, 623.

${ }^{28}$ Nishioka, H, fournal of Neurosurgery, 1966, 25, 574.

${ }^{29}$ Troupp, H, and Biorkesten, G A, Fournal of Neurosurgery, 1971, 35, 20

${ }^{30}$ Shaw, M D M, and Miller, J D, Lancet, 1974, 2, 847.

${ }^{31}$ Knibestol, M, Karadayi, A R, and Tovi, D, Acta Neurologica Scandinavica, $1976, \mathbf{5 4}, 57$.

${ }^{32}$ Sonntag, V K H, and Stein, B M, fournal of Neurosurgery, 1974, 40, 480

(Accepted 30 fanuary 1978)

\title{
Endometrial assessment with Isaacs cell sampler
}

\author{
J D HUTTON， ANNE R MORSE， M C ANDERSON, R W BEARD
}

British Medical Fournal, 1978, 1, 947-949

\section{Summary and conclusions}

The value of the Isaacs endometrial cell sampler in the cytological assessment of the endometrium was studied in 121 unanaesthetised patients aged over 40. Satisfactory aspirates for cytological diagnosis of endometrial state were obtainable in 111 patients $(91 \%)$ whereas endometrial specimens for histological diagnosis were obtained in only 89 patients $(79 \%)$. In only four out of 83

Department of Obstetrics and Gynaecology, St Mary's Hospital Medical School, London W2 1PG

J D HUTTON, MRCog, Abbott research fellow

R W BEARD, MD, FRCOG, professor

Department of Pathology, St Mary's Hospital Medical School, London W2 1PG

ANNE R MORSE, CT(IAC), senior technologist

M C ANDERSON, MB, MRCPATH, senior lecturer cases were there diagnostic discrepancies between the aspirates and the curettings. It is concluded that the technique is safe, quick, comfortable, and reliable for assessing endometrial state. It should therefore prove valuable for screening, particularly in the management of menopausal women requiring oestrogen treatment.

\section{Introduction}

Considerable experience of mass screening programmes for carcinoma of the cervix has shown that premalignant and malignant lesions can often be diagnosed at an asymptomatic stage. The success of the Papanicolaou smear is largely due to the ease with which cell samples can be obtained. There has always been a need for a similar screening test to detect asymptomatic premalignant and malignant lesions of the body of the uterus. Such a test would also be valuable in screening postmenopausal women receiving oestrogen treatment, which may be associated with abnormal endometrial hyperplasia ${ }^{1}$ and carcinoma. ${ }^{2-4}$

Various methods of obtaining endometrial specimens for 
cytological diagnosis of endometrial state have been developed, ${ }^{5-}$; but because they have been either complicated or expensive or unreliable they have never been widely used. Recently a simple, inexpensive, disposable endometrial cell sampler has been developed by Isaacs and Wilhoitte * for quickly collecting material from the uterine cavity. The aspirate obtained is treated in the same manner as a Papanicolaou smear from the cervix. We decided to determine the acceptability and the diagnostic reliability of this method of aspirating the uterine cavity in unanaesthetised women aged over 40.

\section{Patients and methods}

All women aged over 40 who were admitted to the Samaritan hospital for gynaecological surgery during a three-month period were initially considered for inclusion in the study. After exclusion of 38 patients, usually because consent was refused, 100 patients were studied (by JDH). Immediately after the examination these patients (mean age 51.1 \pm SD 8.1) were asked to grade the discomfort experienced during the various stages of the procedure. A further 21 patients admitted to hospital for diagnostic curettage because of postmenopausal or abnormal perimenopausal bleeding were included in the study group for assessment of diagnostic reliability of the technique.

The Isaacs endometrial cell sampler is a flexible stainless-steel cannula (diameter $1.9 \mathrm{~mm}$ ) with multiple perforations $3.8 \mathrm{~cm}$ from the tapered tip (see fig). A movable cervical stop and a syringe create a negative pressure in the system. The position of the uterus was determined so that the pelvic curve on the cannula could be introduced in the appropriate direction. With the patient in the left lateral position, a bivalve speculum was introduced (except in three patients with procidentia) and smears were obtained from the lateral vaginal wall and cervix. A single-toothed tenaculum was applied to the cervix either to steady it ( 49 patients) or alter the axis of the cervical canal in relation to the uterus and vagina (22 patients) before the cannula was gently introduced through the cervical os into the uterine cavity. When the cannula was fully introduced or the fundus of the uterus was reached, the cervical stop was adjusted to engage the cervix. By

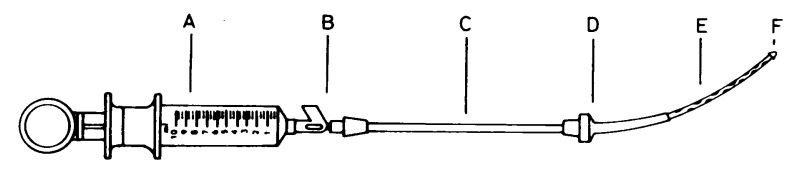

Isaacs endometrial cell sampler. (A) Syringe. (B) Adapter. (C) Shield. (D) Cervical stop. (E) Cannula with multiple perforations. (F) Cannula tip.

TABLE 1-Degrees of discomfort experienced by 100 women during various stages of uterine cavity aspiration with Isaacs endometrial cell sampler

\begin{tabular}{l|c|c|c|c|c}
\hline \multicolumn{1}{c|}{ Stage of procedure } & \multicolumn{3}{c|}{ Degree of discomfort } & Not asked \\
\cline { 2 - 5 } & None & Mild & Moderate & Severe & \\
\hline $\begin{array}{l}\text { Introduction of speculum } \\
\text { Application of tenaculum }\end{array}$ & 50 & 39 & 7 & 1 & 3 \\
$\begin{array}{l}\text { Insertion of cell sampler and } \\
\text { aspiration of endometrial cavity }\end{array}$ & 12 & 49 & 8 & & 29 \\
After completion of procedure & 70 & 24 & 33 & 8 & 4 \\
\hline
\end{tabular}

withdrawing the plunger of the syringe, a vacuum was created in the system for about 15 seconds while slight side-to-side motion was applied to the intrauterine cannula. The aspirate was expressed from the cannula on to a glass slide, smears were prepared by pressing another slide across the aspirate, and both slides were placed separately into the fixative.

All smears were stained together with the routine cervical smears $\varrho$ by the Papanicolaou-Traut method ${ }^{9}$ and screened (by AM). From the $\subseteq$ cytological appearances the aspirates were classified ${ }^{10}$ as normal postmenopausal, normal premenopausal, cystic hyperplasia, adeno- $\stackrel{\mathscr{P}}{\rightarrow}$ matous hyperplasia, atypical hyperplasia, and adenocarcinoma. Endometrial cells were classified as suggestive of cystic hyperplasia $\bar{\sigma}$ when there was intense nuclear staining with some overall enlargement $\bar{\sigma}$ of the encometrial cells but no atypical distribution of chromatin. $\overrightarrow{\mathbb{D}}$ When nuclear atypia was obvious the aspirate was reported as suggesting adenomatous hyperplasia. Cytological and histological os diagnoses were made independently.

Endometrial specimens for histological examination (by MCA) were obtained by curettage in 59 patients, by endometrial biopsy in $\vec{\omega}$ two, and at hysterectomy in 28 . No specimens were obtained from 23 patients and no attempt was made at subsequent operation to $\frac{0}{3}$ obtain an endometrial specimen in nine patients from the initial. series. Histological specimens were classified ${ }^{11}$ according to the most abnormal area of endometrium seen. Atypical hyperplasia was used to describe a form of adenomatous hyperplasia in which there was $\vec{\infty}$ cellular and architectural atypia.

\section{Results}

\section{ACCEPTABILITY OF TECHNIQUE}

Table I shows the degree of discomfort experienced by patients from the initial series during or after the various stages of the pro- $\infty$ cedure. Although eight patients experienced severe discomfort during insertion of the cannula or aspiration, it was necessary to abandon the procedure in only one patient. No other treatment was required or demanded. The mean time for the whole procedure, from the introduction of the speculum to its withdrawal, was 2.55 minutes (range 1-5 minutes). After completion of the procedure bleeding occurred $\varrho$ from the tenaculum site in two patients, from perforation into the $\overrightarrow{\bar{O}}$ myometrium of a fibroid uterus in one, and from the uterus after 3 withdrawal of the cannula in one; in each case the bleeding stopped without treatment. No other complications were noted.

Although introduction of the cannula was incomplete in two patients with fibroids and in one with a congenital uterine abnormality, satisfactory aspirates for cytological diagnosis were obtained. Introduction of the cannula failed in four and a satisfactory aspirate was 0 not obtained in six others. Three of these patients had cervical stenosis, in two the uterine position was fixed by an inoperable ovarian tumour, and in two others the uterine cavity was distorted by fibroids.

\section{DIAGNOSTIC FINDINGS}

A satisfactory aspirate for cytological diagnosis of endometrial state could be obtained in 111 of the 121 patients $(91 \%)$. Curettage was not attempted in nine, and specimens for histological diagnosis were obtained in 89 of the remaining 112 patients $(79 \%)$. Fifteen of $\omega$ the 23 women from whom no specimen was obtainable were postmenopausal. ${ }^{12}$ Cytological and histological diagnoses of endometrial 0 state are compared in table II. Diagnoses agreed in 79 of the $83 \frac{\mathrm{C}}{\mathrm{C}}$ patients $(95 \%)$ from whom both satisfactory aspirates and curettings $\stackrel{\mathbb{S}}{\rightarrow}$

TABLE II-Cytological and histological diagnoses of endometrial state in 121 patients

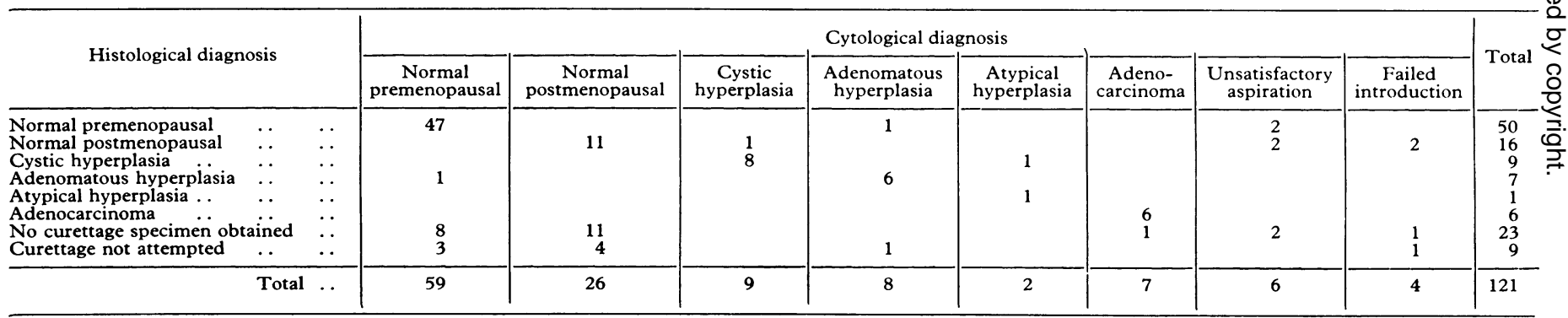


had been obtained. Atypical hyperplasia was diagnosed in one patient by aspiration only, as no curettage specimen was obtained. This was confirmed when an endometrial polyp in the hysterectomy specimen also showed atypical hyperplasia. In another patient adenomatous hyperplasia was diagnosed from the aspirate and histological examination of the hysterectomy specimen showed only a small focus of adenomatous hyperplasia in the glands well below the surface of the uterine cavity. In one patient with postmenopausal bleeding a cytological diagnosis of adenocarcinoma was made but no curettings could be obtained. She was subsequently asymptomatic, but because of the cytological diagnosis a laparotomy was performed three months later when an inoperable ovarian carcinoma was discovered.

\section{Discussion}

Our results show that this technique is valuable in assessing endometrial state in unanaesthetised patients. This confirms the results of earlier studies in anaesthetised patients. ${ }^{*}$ The technique seems to be even more successful in determining endometrial state than operative curettage in women aged over 40 .

In most gynaecology clinics endometrial state is assessed by histological examination of specimens obtained by Vabra curettage. The Isaacs endometrial cell sampler may be more suitable than the Vabra curette for use in outpatient clinics as the cannula is finer, and sounding of the uterine cavity and a suction pump are not required for aspiration. Unlike Vabra curettage, ${ }^{13} 14$ pain and bleeding during or after the procedure are slight or absent. Diagnosis of endometrial state was possible in $91^{\circ}$ " of our patients compared with $77^{\prime \prime}$ " of patients of similar age assessed by Vabra curettage. ${ }^{1}$ Introducing the cannula through the cervical os is sometimes difficult, however, and we recommend that only those experienced in gynaecological procedures should use the aspirator. Nervous patients should perhaps be given premedication with diazepam to reduce the possibility of severe discomfort when the cannula is introduced or during uterine cavity aspiration.

The results of this study suggest that the potential of endometrial cavity aspiration using the Isaacs endometrial cell sampler is considerable. Its use may eliminate the need for many time-consuming inpatient diagnostic curettages. It should also prove invaluable in menopause clinics for monitoring postmenopausal oestrogen treatment. Further experience of endometrial cytology may show that the hormonal state of women with ovulatory disturbances can be similarly assessed.

We thank the medical and nursing staff of the Samaritan hospital for their co-operation, and Dr W O Elson, of the Kendall company, for providing the Isaacs endometrial cell samplers.

\section{References}

${ }^{1}$ Whitehead, M I, and Campbell, S, in Proceedings of the Second International Meeting on Endometrial Cancer and Related Topics, ed $\mathrm{R}$ W Taylor, $M$ Brush, and $R$ J King. London, Baillière, Tindall and Cassell. In press.

Smith, D C, et al, New England fournal of Medicine, 1975, 293, 1164

${ }^{3}$ Ziel, H K, and Finkle, W D, New England Fournal of Medicine, 1975, 293, 1167.

4 McDonald, T W, et al, American fournal of Obstetrics and Gynecology, 1977, 127, 572 .

${ }^{5}$ Ayre, J E, Obstetrics and Gynecology, 1955, 5, 137.

${ }^{6}$ Gravlee, L C, ()bstetrics and Gynecology, 1969, 34, 168.

7 Torres, J E, Holmquist, N D, and Danos, M L, Acta Cytologica, 1969, $13,163$.

'Isaacs, J H, and Wilhoitte, R W, American fournal of Obstetrics and Gynecology, 1974, 118, 679.

${ }^{9}$ Papanicolaou, G N, and Traut, H F, New York State Fournal of Medicine, $1943,43,767$.

11 Reagan, J W, and $\mathrm{Ng}$, A B P, in Clinical Cytology, vol 1, ed G L Wied. Basel, Karger, 1965

11 Dallenbach-Hellweg, G, in Histopathology of the Endometrium. Berlin, Springer Verlag, 1975.

12 Jacobs, H S, and Murray, M A F, in The Management of the Menopause and Post-menopausal Years, ed S Campbell, p 359. Lancaster, MTP Press, 1976.

${ }^{13}$ Holt, E M, Fournal of Obstetrics and Gynaecology of the British Commonvealth, 1970, 77, 1043 .

14 Nassler, E, Thomsen, P B, and Weeth, R, Danish Medical Bulletin, 1975, 11,1165 .
University Department of Paediatrics, East Birmingham Hospital, Birmingham B9 5ST

A DERSO, MB, MRCP, research registrar

M J TARLOW, MSC, MRCP, senior lecturer in paediatrics

Regional Virus Laboratory, East Birmingham Hospital, Birmingham B9 5ST

ELIZABETH H BOXALL, BSC, PHD, senior microbiologist

T H FLEWETT, MRCP, FRCPATH, consultant virologist only $17(14 \%)$ were still positive for HBsAg. Cord-blood HBsAg-positivity was evenly distributed among different ethnic groups, but the transmission rate was highest among the Chinese, and no carriers were discovered among 39 European infants. Raised serum transaminase concentrations were found in some of the carrier infants who were otherwise healthy.

The results suggest that adequate follow-up of HBsAgpositive infants may be achieved by tests at 4 months and 1 year of age, and that the role of breast-feeding in mother-to-infant transmission of $\mathrm{HBsAg}$ is unimportant. The Chinese community may be a suitable population in which to test the effectiveness of specific immunoglobulin administration at birth in preventing the development of the HBsAg carrier state.

\section{Introduction}

Hepatitis B virus is implicated in various clinical conditions, ranging from different types of hepatitis to immune-complex diseases. ${ }^{1-3}$ Its prevalence in the population presents a con- 